\title{
Is COVID-19 another case of the obesity paradox? Results from an international ecological study on behalf of the REPROGRAM Consortium Obesity study group
}

\author{
Sonu Bhaskar ${ }^{1,2,3}$, Sanja Jovanovic ${ }^{1,4}$, Anubhav Katyal ${ }^{1,5,6}$, Narayanan K. Namboodiri ${ }^{1,7}$, \\ Dimitrios Chatzis ${ }^{1,8}$, Maciej Banach ${ }^{1,9,10,11}$
}

\begin{abstract}
1Pandemic Health System REsilience PROGRAM (REPROGRAM) Global Consortium, Obesity REPROGRAM Study Group, Sydney, Australia

${ }^{2}$ Department of Neurology \& Neurophysiology, Liverpool Hospital \& South West Sydney Local Health District (SWSLHD), Liverpool, Australia

${ }^{3}$ NSW Brain Clot Bank, NSW Health Pathology and Neurovascular Imaging

Laboratory, Clinical Sciences Stream, Ingham Institute for Applied Medical Research, Sydney, Australia

${ }^{4}$ Kwantlen Polytechnic University, Office of Research Services, Surrey, British Columbia, Canada

${ }^{5}$ Neurovascular Imaging Laboratory, Clinical Sciences Stream, Ingham Institute for Applied Medical Research, Sydney, Australia

${ }^{6}$ University of New South Wales (UNSW), South Western Sydney Clinical School, Sydney, Australia

${ }^{7}$ Sree Chitra Institute for Medical Sciences and Technology (SCTIMST), Department of Cardiology, Trivandrum, Kerala, India

${ }^{8}$ Medical School, European University Cyprus, Nicosia, Cyprus

${ }^{9}$ Polish Mother's Memorial Hospital Research Institute (PMMHRI), Lodz, Poland

${ }^{10} \mathrm{Cardiovascular}$ Research Centre, University of Zielona Gora, Zielona Gora, Poland

${ }^{11}$ Department of Hypertension, Medical University of Lodz, Lodz, Poland
\end{abstract}

Submitted: 25 April 2021; Accepted: 6 May 2021

Online publication: 10 May 2021

Arch Med Sci 2023; 19 (1): 25-34

DOI: https//doi.org/10.5114/aoms/136447

Copyright @ 2021 Termedia \& Banach

\section{Abstract}

Introduction: Obesity has emerged as one of the major risk factors of severe morbidity and cause-specific mortality among severe acute respiratory syndrome coronavirus-2 (SARS-CoV-2) infected individuals. Patients with obesity also have overlapping cardiovascular diseases and diabetes, which make them increasingly vulnerable. This novel ecological study examines the impact of obesity and/or body mass index (BMI) on rates of population-adjusted cases and deaths due to coronavirus disease 2019 (COVID-19).

Material and methods: Publicly available datasets were used to obtain relevant data on COVID-19, obesity and ecological variables. Group-wise comparisons and multivariate logistic regression analyses were performed. The receiver operating characteristic curve (ROC) was plotted to compute the area under the curve.

Results: We found that male BMI is an independent predictor of cause-specific (COVID-19) mortality, and not of the caseload per million population. Countries with obesity rates of $20-30 \%$ had a significantly higher (approximately double) number of deaths per million population to both those in $<20 \%$ and $>30 \%$ slabs. We postulate that there may be a U-shaped paradoxical relationship between obesity and COVID-19 with the cause-specific mortality burden more pronounced in the countries with 20-30\% obesity rates. These findings are novel along with the methodological approach of doing ecological analyses on country-wide data from publicly available sources.
Corresponding author: Sonu Bhaskar MD PhD Liverpool Hospital South West Sydney Local Health District (SWSLHD)

Department of Neurology and Neurophysiology Liverpool, Australia NSW Brain Clot Bank NSW Health Pathology and Neurovascular Imaging Laboratory Clinical Sciences Stream Ingham Institute for Applied Medical Research Sydney, Australia E-mail:smmb@ globalhealthneurolab.org 
Conclusions: We anticipate, in light of our findings, that appropriate targeted public health approaches or campaigns could be developed to minimize the risk and cause-specific morbidity burden due to COVID-19 in countries with nationwide obesity rates of $20-30 \%$.

Key words: coronavirus 2019 (COVID-19), obesity, metabolic disease, non-communicable diseases (NCDs), demographics.

\section{Introduction}

The ongoing coronavirus diseases 2019 (COVID-19) pandemic, caused by the severe acute respiratory syndrome coronavirus-2 (SARS-CoV-2) viral infection, is a global health crisis of a scale reminiscent of the Spanish flu pandemic almost a century ago [1]. Studies have shown that elderly patients and those with pre-existing comorbidities such as cardiovascular disease, hypertension, obesity and diabetes are at increased risk of COVID-19 associated hospitalization, critical illness and mortality [2-7]. Several studies have demonstrated that obesity is associated with an increased risk of COVID-19 associated hospitalization and/or critical illness [4, 6, 8-17]. A recent meta-analysis found a strong association between obesity and adverse outcomes in COVID-19 patients [18], indicating the role of higher body mass index (BMI) in prognostication [19, 20]. A study from a French hospital on 124 intensive care patients found an association between the need for invasive mechanical ventilation and severe obesity [16]. Another recent study on 393 cases from New York found higher rates of obesity in patients receiving mechanical ventilation [9]. It was also found that obese individuals younger than 50 are more likely to die due to COVID-19 than those who are not obese [21].

Studies have also demonstrated the association of visceral adiposity with COVID-19 severity or critical illness [22-24]. Obesity, and especially diabetes, might also be predictors of long-COVID complications, including myocarditis, arrhythmias, thromboembolism, and heart failure, as indicated in the preliminary results of the Late-COVID study $[5,25]$. The impact of obesity on population demography during COVID-19 and their link to reported COVID-19 case and death rates have not been reported so far.

The current study aims to assess the association between the gender stratified average BMI, life expectancy and gross domestic product (GDP) per capita with the population-adjusted COVID-19 case rate and death rate.

\section{Material and methods}

\section{Data sources}

We used data from the Worldometer, a realtime tracking website (www.worldinfometers. info), to extract data on country-wise COVID-19 confirmed cases including population-adjusted cases and mortality rates (data accessed on 29th June 2020). Our World in Data was used to acquire data on GDP per capita, life expectancy data, average male - and female - BMI, and nationwide obesity rates. The data on Our World in Data is sourced from the official government websites or social media accounts. Based on the unanimous expert decision, only countries with a minimum of 15,000 total COVID-19 cases, as of $29^{\text {th }}$ June 2020 , were included in our analysis [26]. This was done to ensure that a minimum sample size within each country was reached to improve the reliability of the results and minimize any crowding due to a disproportionate number of countries with relatively lower case counts. All data procured and analyzed were sourced from publicly available databases and are available in Supplementary Table SI.

\section{Statistical analysis}

All statistical analyses were performed using STATA software (Version 11, 2001; College Station, TX, USA). The data used in this study are publicly available. The curated dataset used in this study is provided in the Supplementary Table SI. COVID-19 confirmed cases and deaths per million population (total number of COVID-19 associated deaths divided by each respective region's population) and 95\% confidence intervals (Cls) were calculated. Groupwise comparison was performed using STATA version 13 to demonstrate the distribution of baseline characteristics between countries based on the nationwide obesity rates (subgroups: < $20 \%$ vs. $20-30 \%$ vs. > 30\%) and between average BMI subgroups of $<25 \mathrm{~kg} / \mathrm{m}^{2}$ vs. $>25 \mathrm{~kg} / \mathrm{m}^{2}$ for males and females. Subsequently, univariate and multivariate logistic regression analyses were performed to determine the association between average male and female BMI, life expectancy and GDP per capita with the population-adjusted COVID-19 case rates (for cases: $\geq 3000, \geq 4000$, $\geq 5000$ per 1 million population) and death rates (for deaths: $\geq 100, \geq 150$ and $\geq 200$ per 1 million population). The thresholds for various groups of caseloads per million were used based on the closest approximation of median cases/million for the $20-30 \%$ nationwide obesity rate group. This translates to 3000 cases per million. Given that 
the majority of countries belong to the 20-30\% obese group ( $n=33)$, the threshold was chosen to reflect the overall spread. We also selected the caseloads of 4000 and 5000 to investigate any putative linear relationship. For deaths per million population, we chose the mortality threshold based on the nearest median for the $20-30 \%$ obesity rate group - which translated to 100 deaths per million. We also chose two more points, 150 and 200, to investigate linear trends in mortality. The receiver operating characteristic curve (ROC) for the final multivariate regression model (obtained by backwards regression with variables $p<0.1)$ was plotted and the area under the curve computed to evaluate the predictive ability of the regression model.

\section{Results}

A correlation matrix of the investigated variables is shown in Figure 1. Male BMI shows a strong correlation with the female BMI (0.6274; $p \leq 0.0001)$, obesity rate $(0.72 ; p<0.00001)$, GDP per capita $(0.486 ; p=0.0001)$, and life expectancy $(0.49 ; p=0.0001)$. Though weaker, male BMI was also significantly correlated with the total number of COVID-19 associated deaths per million $\left(R^{2}=0.3261 ; p=0.0125\right)$ and the total number of cases per million $(0.3757 ; p=0.0037)$. Female
BMI was not correlated with deaths per million $(-0.0276 ; p=0.8370)$, whereas the correlation of female BMI with the total number of cases per million was significant $(0.3191 ; p=0.0146)$. There was a strong correlation of female BMI with nationwide obesity rate $(0.8405 ; p \leq 0.000001)$. Female BMI was not correlated with GDP per capita $(0.1756 ; p=0.1874)$ or life expectancy $(-0.0492$; $p=0.7136)$.

Group-wise comparison of various metrics stratified by countries with obesity rates of $<20 \%$, 20-30\% and $>30 \%$ are shown in Table I. The highest caseload is demonstrated in the $>30 \%$ group. The highest mortality was demonstrated in the 20-30\% group, while it was the least pronounced in the > 30\% group. GDP per capita in the > 30\% obesity rate group is more than twice as high as the GDP per capita in the $20-30 \%$ group. There is a statistically significant difference in the median population-adjusted COVID-19 cases, COVID-19 deaths, average male BMI, average female BMI, GDP per capita and prevalence of obesity between at least two of the three groups. From the data, although countries with a higher prevalence of obesity have more COVID-19 cases, the mortality is bell-shaped with the greatest mortality being in the $20-30 \%$ obesity rate group. A paired $t$-test revealed a statistically significant difference

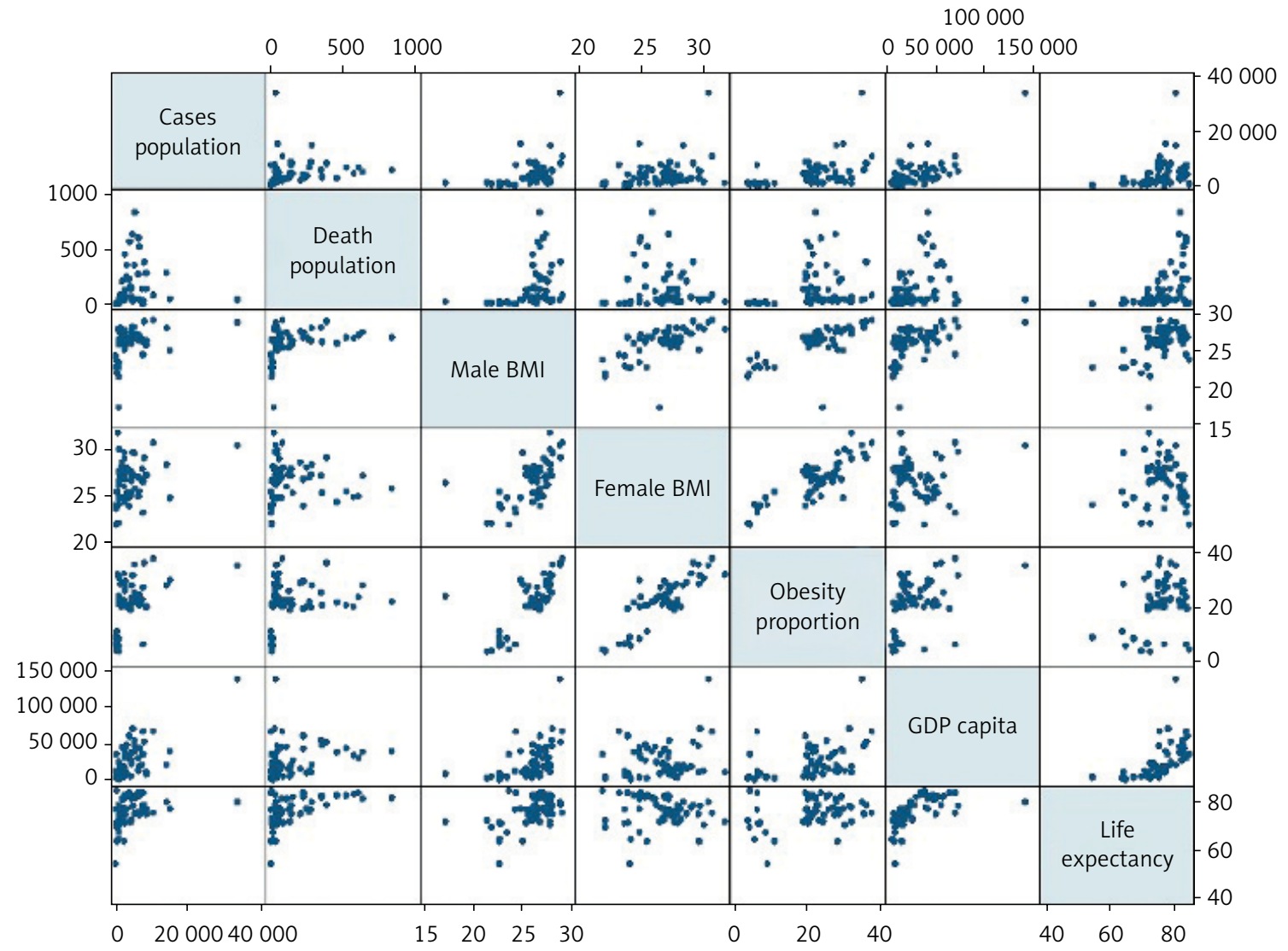

Figure 1. Correlation matrix showing the correlation between various ecological variables 
Table I. Description of ecological variables stratified by nationwide obesity rates of $<20 \%, 20-30 \%$ and $>30 \%$

\begin{tabular}{|c|c|c|c|c|c|c|}
\hline Variable & Data & $\begin{array}{l}\text { Overall } \\
(n=58)\end{array}$ & $\begin{array}{c}<20 \% \\
\text { obesity rate } \\
(n=17)\end{array}$ & $\begin{array}{c}20-30 \% \\
\text { obesity rate } \\
(n=33)\end{array}$ & $\begin{array}{c}>30 \% \\
\text { obesity rate } \\
(n=8)\end{array}$ & $\begin{array}{l}\text { Kruskal-Wallis } \\
\text { test ( } p \text {-value) }\end{array}$ \\
\hline \multirow[t]{2}{*}{$\begin{array}{l}\text { Cases per } 1 \text { million } \\
\text { population }\end{array}$} & Mean (SD) & $\begin{array}{l}4173.76 \\
(5144.65)\end{array}$ & $\begin{array}{l}2156.53 \\
(2605.47)\end{array}$ & $\begin{array}{l}4215.73 \\
(3454.92)\end{array}$ & $\begin{array}{l}8287.25 \\
(10780)\end{array}$ & \multirow[t]{2}{*}{$0.0082^{*}$} \\
\hline & Median (IQR) & $\begin{array}{c}2676 \\
(1129-5289)\end{array}$ & $\begin{array}{c}837 \\
(324-3653)\end{array}$ & $\begin{array}{c}2736 \\
(1826-6328)\end{array}$ & $\begin{array}{c}5038 \\
(1734-9246)\end{array}$ & \\
\hline \multirow[t]{2}{*}{$\begin{array}{l}\text { Deaths per } 1 \text { million } \\
\text { population }\end{array}$} & Mean (SD) & $\begin{array}{c}147.76 \\
(189.71)\end{array}$ & $\begin{array}{c}93.59 \\
(157.17)\end{array}$ & $\begin{array}{l}189.76 \\
(210.44)\end{array}$ & $\begin{array}{c}89.63 \\
(121.80)\end{array}$ & \multirow[t]{2}{*}{$0.0035^{\star}$} \\
\hline & Median (IQR) & $\begin{array}{c}60.5 \\
(27-226)\end{array}$ & $\begin{array}{c}12 \\
(8-131)\end{array}$ & $\begin{array}{c}87 \\
(41-271)\end{array}$ & $\begin{array}{c}44.5 \\
(35.5-71)\end{array}$ & \\
\hline \multirow[t]{2}{*}{ Male BMI } & Mean (SD) & $\begin{array}{l}25.99 \\
(2.20)\end{array}$ & $\begin{array}{l}24.24 \\
(1.96)\end{array}$ & $\begin{array}{l}26.32 \\
(1.88)\end{array}$ & $\begin{array}{l}28.33 \\
(0.66)\end{array}$ & \multirow[t]{2}{*}{$0.0001^{*}$} \\
\hline & Median (IQR) & $\begin{array}{c}26.48 \\
(25.39-27.48)\end{array}$ & $\begin{array}{c}23.68 \\
(22.65-26.37)\end{array}$ & $\begin{array}{c}26.49 \\
(25.99-27.45)\end{array}$ & $\begin{array}{c}28.16 \\
(27.94-28.97)\end{array}$ & \\
\hline \multirow[t]{2}{*}{ Female BMI } & Mean (SD) & $\begin{array}{l}26.56 \\
(2.22)\end{array}$ & $\begin{array}{l}24.60 \\
(2.06)\end{array}$ & $\begin{array}{l}26.74 \\
(1.21)\end{array}$ & $\begin{array}{l}29.98 \\
(0.91)\end{array}$ & \multirow[t]{2}{*}{$0.0001^{\star}$} \\
\hline & Median (IQR) & $\begin{array}{c}26.84 \\
(24.86-27.85)\end{array}$ & $\begin{array}{c}24.03 \\
(23.59-25.39)\end{array}$ & $\begin{array}{c}26.91 \\
(26.01-27.49)\end{array}$ & $\begin{array}{c}29.79 \\
(29.29-30.52)\end{array}$ & \\
\hline \multirow[t]{2}{*}{ GDP per capita $(\$)$} & Mean (SD) & $\begin{array}{c}27319.67 \\
(23884.66)\end{array}$ & $\begin{array}{c}17600.47 \\
(20265.77)\end{array}$ & $\begin{array}{c}26145.12 \\
(14353.04)\end{array}$ & $\begin{array}{c}52818 \\
(42259.32)\end{array}$ & \multirow[t]{2}{*}{$0.0023^{*}$} \\
\hline & Median (IQR) & $\begin{array}{c}18848.50 \\
(10536-39733)\end{array}$ & $\begin{array}{c}10511 \\
(5323-15296)\end{array}$ & $\begin{array}{c}23064 \\
(14088-39162)\end{array}$ & $\begin{array}{c}50244.50 \\
(16380-69041)\end{array}$ & \\
\hline \multirow[t]{2}{*}{$\begin{array}{l}\text { Life expectancy } \\
\text { (years) }\end{array}$} & Mean (SD) & $\begin{array}{l}76.22 \\
(5.86)\end{array}$ & $\begin{array}{l}73.37 \\
(8.10)\end{array}$ & $\begin{array}{l}77.74 \\
(4.38)\end{array}$ & $\begin{array}{l}76.00 \\
(3.36)\end{array}$ & \multirow[t]{2}{*}{0.1396} \\
\hline & Median (IQR) & $\begin{array}{c}76.71 \\
(72.59-81.33)\end{array}$ & $\begin{array}{c}72.59 \\
(69.66-77.01)\end{array}$ & $\begin{array}{c}77.29 \\
(75.05-81.63)\end{array}$ & $\begin{array}{c}76.59 \\
(73.56-78.42)\end{array}$ & \\
\hline \multirow[t]{2}{*}{$\begin{array}{l}\text { Nationwide obesity } \\
\text { rate (\%) }\end{array}$} & Mean (SD) & $\begin{array}{l}21.59 \\
(7.73)\end{array}$ & $\begin{array}{l}11.12 \\
(6.72)\end{array}$ & $\begin{array}{l}24.01 \\
(3.13)\end{array}$ & $\begin{array}{l}33.85 \\
(2.64)\end{array}$ & \multirow[t]{2}{*}{$0.0001^{\star}$} \\
\hline & Median (IQR) & $\begin{array}{c}22.2 \\
(19.9-27.8)\end{array}$ & $\begin{array}{c}8.6 \\
(6.1-19.5)\end{array}$ & $\begin{array}{c}23.1 \\
(21.4-27)\end{array}$ & $\begin{array}{c}33.6 \\
(31.85-35.8)\end{array}$ & \\
\hline
\end{tabular}

between average male and female BMIs in these countries overall $(p=0.0130)$ (Table II).

\section{Population-adjusted case rate univariate and multivariate logistic regression}

The univariate associations with population-adjusted COVID-19 cases per 1 million population were examined for average male BMI, average female BMI, life expectancy, GDP per capita, and nationwide obesity rate. COVID-19 cases per 1 million population were further stratified into $\geq 3000$ per million, $\geq 4000$ per million, and $\geq 5000$ per million.

In population-adjusted case rate univariate logistic regression, all variables except average female BMI were significantly associated with each of the COVID-19 cases per 1 million population group (Table III). Average male BMI, GDP per capita, life expectancy, and nationwide obesity rate were included in the multivariate logistic regression model; however, no variable was a significant predictor in the multivariate model. The analyzed variables provided a poor predictive model for
COVID-19 cases per 1 million population (area under the ROC curve for each stratum: 0.7867, 0.7614 , and 0.7547 , respectively) (Table IV).

Population-adjusted mortality rate univariate and multivariate logistic regression

The univariate associations with population-adjusted COVID-19 deaths per 1 million population were examined for average male BMI, average female BMI, life expectancy, GDP per capita, and nationwide obesity rate. COVID-19 deaths per 1 million population were stratified into $\geq 100$ per 1 million, $\geq 150$ per 1 million, and $\geq 200$ per 1 million (Table $\mathrm{V}$ ). Only average male BMI and life expectancy were found to be statistically significant in the univariate regression analysis for each of the COVID-19 deaths per 1 million population group. Average male BMI and life expectancy were thus included in the multivariate logistic regression model. While not found to be statistically significant in the univariate logistic regression analysis, we included GDP per capita in the mul- 


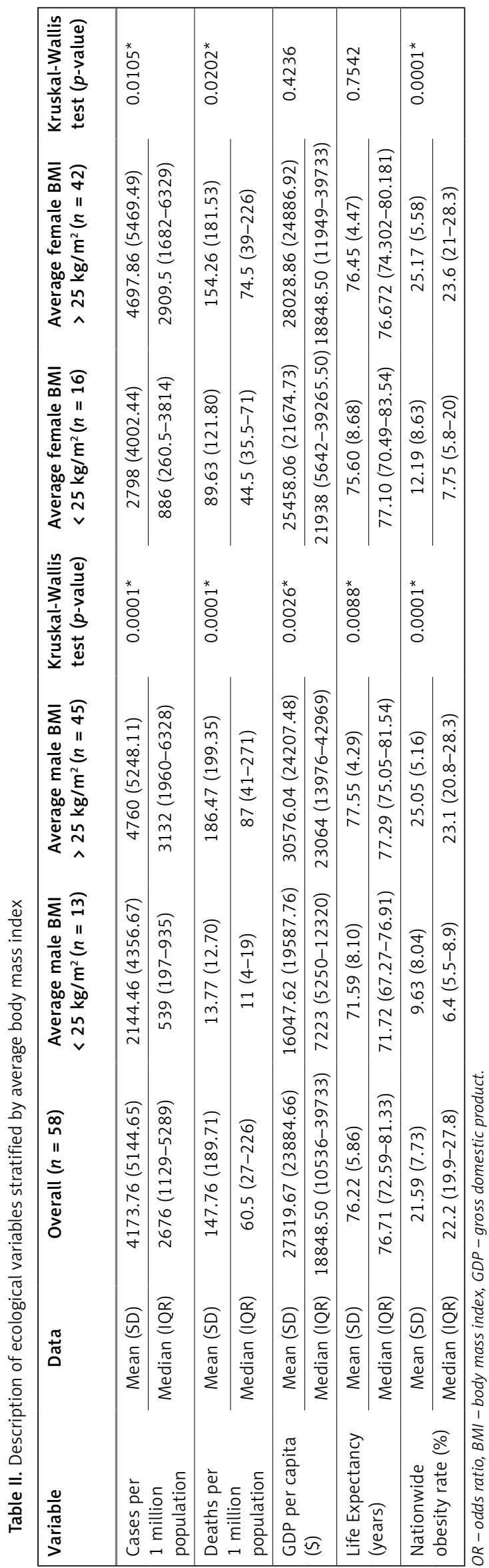

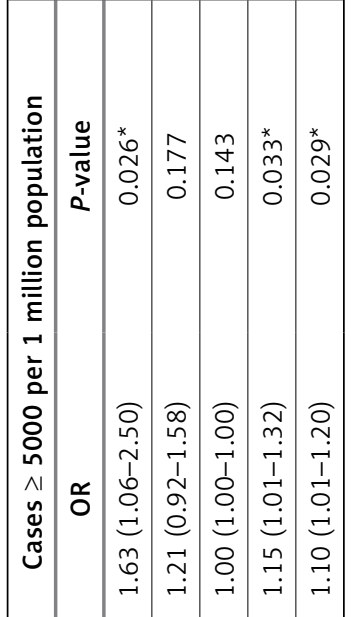

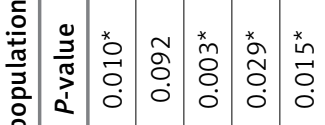

产

容

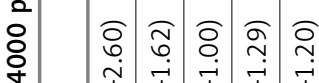

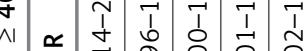

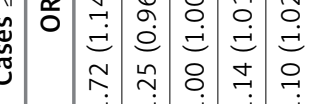
苋

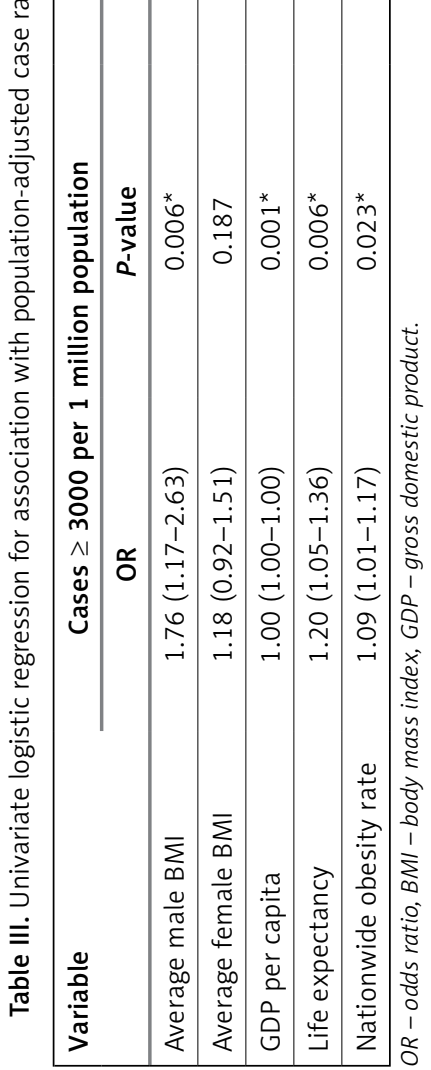


Table IV. Multivariate logistic regression for association with case load per million population

\begin{tabular}{|c|c|c|c|c|c|c|}
\hline \multirow[t]{2}{*}{ Variable } & \multicolumn{2}{|c|}{$\begin{array}{c}\text { Cases } \geq 3000 \\
\text { per } 1 \text { million population }\end{array}$} & \multicolumn{2}{|c|}{$\begin{array}{c}\text { Cases } \geq 4000 \\
\text { per } 1 \text { million population }\end{array}$} & \multicolumn{2}{|c|}{$\begin{array}{c}\text { Cases } \geq 5000 \\
\text { per } 1 \text { million population }\end{array}$} \\
\hline & OR & $P$-value & OR & $P$-value & OR & $P$-value \\
\hline Average male BMI & $1.41(0.90-2.22)$ & 0.137 & $1.42(0.91-2.23)$ & 0.127 & $1.31(0.82-2.08)$ & 0.261 \\
\hline Life expectancy & $1.04(0.87-1.24)$ & 0.650 & $0.99(0.84-1.17)$ & 0.888 & $1.04(0.87-1.23)$ & 0.689 \\
\hline GDP per capita & $1.00(1.00-1.00)$ & 0.129 & $1.00(1.00-1.00)$ & 0.199 & $1.00(1.00-1.00)$ & 0.164 \\
\hline $\begin{array}{l}\mathrm{ROC} \text { of the multivariate } \\
\text { regression model }\end{array}$ & \multicolumn{2}{|c|}{$0.7867^{* *}$} & \multicolumn{2}{|c|}{$0.7614^{* *}$} & \multicolumn{2}{|c|}{$0.7547^{\star *}$} \\
\hline
\end{tabular}

${ }^{* *} n=58$ countries. Average male BMI, life expectancy and GDP per capita provide a poor predictive model for cases per 1 million population (each variable is non-significant in multivariate analysis). OR - odds ratio, BMI - body mass index, GDP - gross domestic product, $R O C$ - receiver operating characteristic curve.

tivariate logistic regression model as a socially important variable (Table $\mathrm{VI}$ ). In the multivariate analysis, average male BMI (odds ratio (OR) 1.99, $95 \% \mathrm{Cl}: 1.02-3.88, p=0.043 ; \mathrm{OR}=2.67,95 \% \mathrm{Cl}$ : $1.16-6.15, p=0.021 ;$ and $\mathrm{OR}=2.60,95 \% \mathrm{Cl}: 1.14$ 5.91, $p=0.022)$ and life expectancy $(\mathrm{OR}=1.62$, $95 \% \mathrm{Cl}: 1.21-2.15, p=0.001 ; \mathrm{OR}=1.85,95 \% \mathrm{Cl}$ : $1.28-2.67, p=0.001$; and $\mathrm{OR}=1.71,95 \% \mathrm{Cl}$ : 1.23-2.36, $p=0.001$ ) were found to have significant associations in each of the stratified groups.

The model showed that GDP per capita was significantly associated with COVID-19 deaths but only in the deaths $\geq 100$ per 1 million group. Importantly, the model demonstrated an excellent predictive ability (area under ROC curve ROC $0.8788,0.9168$, and 0.9033 across the analyzed group; Table VI). The model showed the best predictive ability in the deaths $\geq 150$ per 1 million strata (sensitivity $70.6 \%$; specificity $87.9 \%$; positive predictive value $70.6 \%$; negative predictive value $87.8 \%$; correctly classified $82.76 \%$ ). The final model consisting of average male BMI, life expectancy and GDP per capita predicted population-adjusted COVID-19 death rates globally (using a threshold of 150 deaths per million population) (Figure 2).

\section{Discussion}

The current study might have major public health implications with novel findings regarding the associations between COVID-19 and obesity.

Table V. Univariate logistic regression for association with population-adjusted cause-specific death rates due to COVID-19

\begin{tabular}{|lcccccc|}
\hline Variable & \multicolumn{2}{c}{$\begin{array}{c}\text { Cause-specific deaths } \geq 100 \\
\text { per 1 million population }\end{array}$} & $\begin{array}{c}\text { Cause-specific deaths } \geq 150 \\
\text { per } 1 \text { million population }\end{array}$ & $\begin{array}{c}\text { Cause-specific deaths } \geq 200 \\
\text { per } 1 \text { million population }\end{array}$ \\
\cline { 2 - 7 } & OR & $P$-value & OR & $P$-value & OR & $P$-value \\
\hline Average male BMI & $1.56(1.07-2.27)$ & $0.02^{*}$ & $1.67(1.08-2.60)$ & $0.022^{*}$ & $1.72(1.08-2.74)$ & $0.021^{*}$ \\
\hline Average female BMI & $1.01(0.795-1.29)$ & 0.922 & $0.96(0.74-1.24)$ & 0.762 & $0.99(0.76-1.28)$ & 0.888 \\
\hline GDP per capita & $1.00(1.00-1.00)$ & 0.317 & $1.00(1.00-1.00)$ & 0.147 & $1.00(1.00-1.00)$ & 0.143 \\
\hline Life expectancy & $1.33(1.13-1.56)$ & $0.001^{*}$ & $1.44(1.17-1.76)$ & $<0.0001^{*}$ & $1.40(1.15-1.70)$ & $0.001^{*}$ \\
\hline $\begin{array}{l}\text { Nationwide obesity } \\
\text { rate }\end{array}$ & $1.04(0.98-1.11)$ & 0.208 & $1.00(1.00-1.00)$ & 0.325 & $1.00(1.00-1.00)$ & 0.315 \\
\hline
\end{tabular}

$O R$ - odds ratio, BMI - body mass index, GDP - gross domestic product.

Table VI. Multivariate logistic regression for association with population-adjusted mortality rates due to COVID-19

\begin{tabular}{|c|c|c|c|c|c|c|}
\hline \multirow[t]{2}{*}{ Variable } & \multicolumn{2}{|c|}{$\begin{array}{l}\text { Cause-specific deaths } \\
\geq 100 \text { per } 1 \text { million } \\
\text { population }\end{array}$} & \multicolumn{2}{|c|}{$\begin{array}{l}\text { Cause-specific deaths } \\
\geq 150 \text { per } 1 \text { million } \\
\text { population }\end{array}$} & \multicolumn{2}{|c|}{$\begin{array}{c}\text { Cause-specific deaths } \\
\geq 200 \text { per } 1 \text { million } \\
\text { population }\end{array}$} \\
\hline & OR & $P$-value & OR & $P$-value & OR & $P$-value \\
\hline Average male BMI & $1.99(1.02-3.88)$ & $0.043^{*}$ & $2.67(1.16-6.15)$ & $0.021^{*}$ & $2.60(1.14-5.91)$ & $0.022^{*}$ \\
\hline Life expectancy & $1.62(1.21-2.15)$ & $0.001^{*}$ & $1.85(1.28-2.67)$ & $0.001^{*}$ & $1.71(1.23-2.36)$ & $0.001^{*}$ \\
\hline GDP per capita & $\begin{array}{c}0.9999369 \\
(0.9998788- \\
0.999995)\end{array}$ & $0.033^{*}$ & $\begin{array}{c}0.9999379 \\
(0.9998717- \\
1.000004)\end{array}$ & 0.066 & $\begin{array}{c}0.9999495 \\
(0.9998923- \\
1.000007)\end{array}$ & 0.083 \\
\hline $\begin{array}{l}\text { ROC of the multivariate } \\
\text { regression model }\end{array}$ & $0.8788^{\star *}$ & & $0.9168^{\star *}$ & & $0.9033^{* *}$ & \\
\hline
\end{tabular}

${ }^{\star *} n=58$ countries. OR - odds ratio, BMI - body mass index, GDP - gross domestic product, $R O C$ - receiver operating characteristic curve. 
This builds on our previous work where we provided recommendations based on Intensive Care National Audit and Research Centre (ICNARC) United Kingdom (UK) data on COVID-19 critical care patients - that the BMI $\geq 30$ was a significant predictor of mortality in this population [2], hence raising the need for targeted algorithm and riskbased management/triage approach [2, 27-29]. We found that male BMI and life expectancy were independent predictors of COVID-19 mortality and not the COVID-19 confirmed cases per million population.

Countries with a nationwide obesity rate of 2030\% (e.g., Brazil, Russia, the UK, Iran, Spain) [30] had a significantly higher (approximately double) number of deaths per million population compared to both those in < 20\% and > 30\% obesity rate slabs. We postulate that there may be a U-shaped paradoxical relationship between obesity and COVID-19 mortality burden more pronounced in the countries with $20-30 \%$ obesity rates. Our findings are relevant especially in the light of the recently released Public Health England (PHE) report on excess weight and COVID-19 [31]. The increased prevalence and disease burden due to excess weight in general, and obesity in particular, is a public health concern globally, with the burden being higher in western countries [32]. The PHE report highlights that the people belonging to Black, Asian and Minority Ethnic (BAME) communities, those living in deprived areas, and those aged 55-74 years are disproportionately affected by excess weight [31]. Moreover, it is well known that the health risks related to excess weight are more prevalent in BAME communities, even at a lower $\mathrm{BMI}$ than in those from Caucasian backgrounds. Given the disproportionate impact of COVID-19 on vulnerable communities [33], such as racial/ethnic minority groups, which are particularly vulnerable to increased prevalence and incidence of obesity and diabetes [34], targeted multilevel interventions against obesity may provide protection [35], and hence mitigate the impact of COVID-19.

Notably, the obesity paradox, i.e. the association of higher BMI with lower mortality, longer hospital stays and longer ventilation period, in ICU patients requiring mechanical ventilation, has also been a subject of debate [36, 37]. However, the hypothesis has been challenged [38]. The protective role of obesity, as proposed in this hypothesis, in reduced mortality may be due to lack of adjustment for comorbidities or potential confounders including a history of smoking, disease severity and socioeconomic variables [38]. Moreover, it has been suggested that BMI does not account for body composition, adiposity, and their variations due to gender and ethnicity [39]. It also fails to detect "normal obese subjects" [38]. Last, but

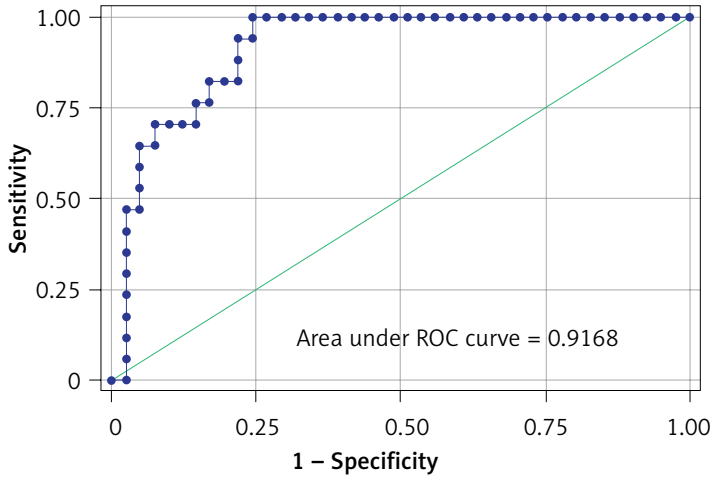

Figure 2. Receiver operating characteristic curve corresponding to the final multivariate logistic regression model for association with cause-specific deaths $\geq 150$ per 1 million population due to COVID-19

not least, since severe infections in general and more specifically COVID-19 represent catabolic and high energy-consuming situations, obese patients may have a more favorable prognosis due to their augmented metabolic reserve [40]. This hypothesis holds also true in heart failure (HF) as the well-known catabolic state in which it seems that patients who are obese have better clinical outcomes compared to their leaner counterparts [40, 41]. Our findings are distinct, as it takes a population or systems-level approach to address the impact of COVID-19 on obese patients. We have included ecological variables such as GDP which are often not considered or adjusted for in clinical trials or case-controlled studies.

We hypothesized that countries with a nationwide obesity rate of $>30 \%$ may have better-developed health systems delivering a higher quality of care including tailored treatment options and/or have well-coordinated health services targeted toward obese people embedded within the system. One of the obesity programs' strategies may have been strongly advising obese people to adhere to physical distancing and wearing masks whenever distancing of 6 feet cannot be ensured [31]. Better treatments and/or well-organized support programs for obese people are likely associated with higher GDP per capita as well. The values of GDP per capita are indeed much higher for countries with a nationwide obesity rate $>30 \%$ : twice as high GDP per capita in countries with obesity rates of 20-30\% (mean \$52,818 (SD 42259.32); median \$50,244.50 (IQR 16380-69041)) vs. mean $\$ 26,145.12$ (SD14353.04); median \$23,064 (IQR 14088-39162). Five countries in the $>30 \%$ stratum are countries with high GDP per capita, i.e. the US, Saudi Arabia, the UAE, Kuwait, and Qatar, presenting $62.5 \%$ of the population of the group. While GDP per capita in the $>30 \%$ obesity rate group is even higher compared to the $<20 \%$ group (\$17,600.47 (SD 20265.77); median: \$10,511 
(IQR 5323-15296)), the latter has a significantly smaller proportion of obese people, which may be responsible for higher mortality being observed in both $<20 \%$ and $>30 \%$ obesity rate groups compared to the $20-30 \%$ group. The countries with nationwide obesity rates $>30 \%$ have significantly higher case rates (mean 8287.25 (SD 10780); median 5038 (IQR 1734-9246)) vs. < 20\% obesity rate group with mean 2156.53 (SD2605.47); median 837 (IQR 324-3653) and 20-30\% obesity rate group (mean 4215.73 (SD 3454.92); median 2736 (IQR 1826-6328)). The countries with higher GDP per capita may be testing more for COVID-19 and thus timely identifying the higher proportion of COVID-19 positive obese people who then receive appropriate care in a timelier manner.

Various mechanisms have been proposed to explain the association between obesity and increased disease severity in COVID-19 hospitalized patients. It is recognized that SARS-CoV-2 has a strong affinity for human angiotensin-converting enzyme 2 (ACE-2) [5]. Adipose tissue also has increased expression of ACE-2 receptors [42]. Moreover, obesity also exacerbates the hyper-inflammatory response (cytokine storm) causing deteriorating lung function capacity and increased need for mechanical ventilation [29]. Telemedicine could be a great enabler in implementing effective prophylactic strategies to reduce the morbidity and mortality burden in this subgroup of patients [43-45].

Our multivariate regression model did not account for cardiovascular disease and diabetes or other comorbidities associated with obesity. However, we believe that, since obesity and other comorbidities have a significant overlap, introducing these variables would introduce multicollinearity effects in the multivariate logistic regression model. $\mathrm{BMI}$ as a marker of obesity has been widely contested and is supposedly sub-optimal in elderly patients [46]. Despite the limited accuracy of BMI, it remains one of the most widely used tools to characterize excess weight or obesity around the world [47].

In conclusion, the findings reported in this study are novel, as is the methodological approach of conducting ecological analyses on country-wide data from publicly available sources. Our findings should be interpreted within the context of study design. We anticipate, in light of our findings, that appropriate targeted public health approaches or campaigns could be developed to minimize the risk of infection and morbidity burden due to COVID-19 in countries with a nationwide obesity rate of $20-30 \%$, especially males, who may be more vulnerable to mortality due to COVID-19.

\section{Author notes}

The COVID-19 pandemic is causing an unprecedented public health crisis impacting healthcare systems, healthcare workers and communities. The COVID-19 Pandemic Health System REsilience PROGRAM (REPROGRAM) is a not-for-profit consortium of international healthcare physicians, researchers and policymakers formed to champion the safety of healthcare workers, policy development and advocacy for global pandemic preparedness and action.

\section{Acknowledgments}

We would like to acknowledge the REPROGRAM consortium members who have worked tirelessly over the last days in contributing to various guidelines, recommendations, policy briefs, and ongoing discussions during these unprecedented and challenging times despite the incredibly short timeframe. We would like to dedicate this work to our healthcare workers who have died due to COVID-19 while serving the patients at the frontline and to those who continue to serve during these challenging times despite the lack of personal protective equipment.

\section{Conflict of interest}

The authors declare no conflict of interest.

\section{References}

1. Jones DS. History in a crisis - lessons for Covid-19. N Engl J Med 2020; 382: 1681-3.

2. Bhaskar S, Rastogi A, Chattu VK, et al. Key strategies for clinical management and improvement of healthcare services for cardiovascular disease and diabetes patients in the coronavirus (COVID-19) settings: recommendations from the REPROGRAM consortium. Front Cardiovasc Med 2020; 7: 112.

3. Zhou F, Yu T, Du R, et al. Clinical course and risk factors for mortality of adult inpatients with COVID-19 in Wuhan, China: a retrospective cohort study. Lancet 2020; 395: 1054-62.

4. Cai Q, Chen F, Wang T, et al. Obesity and COVID-19 severity in a designated hospital in Shenzhen, China. Diabetes Care 2020; 43: 1392-8.

5. Katsiki N, Banach M, Mikhailidis DP. Lipid-lowering therapy and renin-angiotensin-aldosterone system inhibitors in the era of the COVID-19 pandemic. Arch Med Sci 2020; 16: 485-9.

6. Monteiro AC, Suri R, Emeruwa IO, et al. Obesity and smoking as risk factors for invasive mechanical ventilation in COVID-19: a retrospective, observational cohort study. PLoS One 2020; 15: e0238552.

7. Azzolino D, Cesari M. Obesity and COVID-19. Front Endocrinol 2020; 11: 581356.

8. Caussy C, Pattou F, Wallet F, et al. Prevalence of obesity among adult inpatients with COVID-19 in France. Lancet Diabetes Endocrinol 2020; 8: 562-4.

9. Goyal P, Choi JJ, Pinheiro LC, et al. Clinical characteristics of Covid-19 in New York City. N Engl J Med 2020; 382: 2372-4.

10. Hamer M, Kivimäki M, Gale CR, Batty GD. Lifestyle risk factors, inflammatory mechanisms, and COVID-19 hospitalization: a community-based cohort study of 387,109 adults in UK. Brain Behav Immun 2020; 87: 184-7. 
11. Klang E, Kassim G, Soffer S, Freeman R, Levin MA, Reich DL. Morbid obesity as an independent risk factor for COVID-19 mortality in hospitalized patients younger than 50. Obesity 2020; 28: 1595-9.

12. Lighter J, Phillips M, Hochman S, et al. Obesity in patients younger than 60 years is a risk factor for Covid-19 hospital admission. Clin Infect Dis 2020; 71: 896-7.

13. Petrilli CM, Jones SA, Yang J, et al. Factors associated with hospital admission and critical illness among 5279 people with coronavirus disease 2019 in New York City: prospective cohort study. BMJ 2020; 369: m1966-m.

14. Richardson S, Hirsch JS, Narasimhan M, et al. Presenting characteristics, comorbidities, and outcomes among 5700 patients hospitalized with COVID-19 in the New York City Area. JAMA 2020; 323: 2052-9.

15. Rottoli M, Bernante P, Belvedere A, et al. How important is obesity as a risk factor for respiratory failure, intensive care admission and death in hospitalised COVID-19 patients? Results from a single Italian centre. Eur J Endocrinol 2020; 183: 389-97.

16. Simonnet A, Chetboun M, Poissy J, et al. High prevalence of obesity in severe acute respiratory syndrome Coronavirus-2 (SARS-CoV-2) requiring invasive mechanical ventilation. Obesity 2020; 28: 1195-9.

17. Yang Y, Ding L, Zou X, et al. Visceral adiposity and high intramuscular fat deposition independently predict critical illness in patients with SARS-CoV-2. Obesity 2020 28: $2040-8$

18. Malik P, Patel U, Patel K, et al. Obesity a predictor of outcomes of COVID-19 hospitalized patients - a systematic review and meta-analysis. J Med Virol 2020; 93: 1188-93.

19. Tamara A, Tahapary DL. Obesity as a predictor for a poor prognosis of COVID-19: a systematic review. Diabetes Metab Syndr 2020; 14: 655-9.

20. Al Heialy S, Yaseen Hachim M, Yaseen Hachim I, et al. Combination of obesity and co-morbidities leads to unfavorable outcomes in COVID-19 patients. Saudi J Biol Sci 2021; 28: 1445-50.

21. Klang E, Kassim G, Soffer S, Freeman R, Levin MA, Reich DL. Morbid obesity as an independent risk factor for COVID-19 mortality in hospitalized patients younger than 50. Obesity 2020; 28: 1595-9.

22. Yang Y, Ding L, Zou X, et al. Visceral adiposity and high intramuscular fat deposition independently predict critical illness in patients with SARS-CoV-2. Obesity 2020; 28: 2040-8.

23. Battisti S, Pedone C, Napoli N, et al. Computed tomography highlights increased visceral adiposity associated with critical illness in COVID-19. Diabetes Care 2020; 43: e129-30.

24. Petersen A, Bressem K, Albrecht J, et al. The role of visceral adiposity in the severity of COVID-19: highlights from a unicenter cross-sectional pilot study in Germany. Metabolism 2020; 110: 154317

25. Lewek J, Jatczak-Pawlik I, Maciejewski M, Jankowski P, Banach M. COVID-19 and cardiovascular complications - the preliminary results of the LATE-COVID study. Arch Med Sci 2021; 17: 818-22.

26. COVID-19 Models, Scenarios and Thresholds Canada: Alberta Health Services 2020. Available from: https:// www.albertahealthservices.ca/assets/info/ppih/if-ppihcovid-19-sag-models-scenarios-and-thresholds-rapidreview.pdf

27. Bhaskar S, Bradley S, Israeli-Korn S, et al. Chronic neurology in COVID-19 era: clinical considerations and recommendations from the REPROGRAM Consortium. Front Neurol 2020; 11: 664.
28. Bhaskar S, Sharma D, Walker AH, et al. Acute neurological care in the COVID-19 era: the Pandemic Health System REsilience PROGRAM (REPROGRAM) Consortium Pathway. Front Neurol 2020; 11: 579.

29. Bhaskar S, Sinha A, Banach M, et al. Cytokine storm in COVID-19 - immunopathological mechanisms, clinical considerations, and therapeutic approaches: the REPROGRAM Consortium Position Paper. Front Immunol 2020; 11: 1648

30. Abarca-Gómez L, Abdeen ZA, Hamid ZA, et al. Worldwide trends in body-mass index, underweight, overweight, and obesity from 1975 to 2016: a pooled analysis of 2416 population-based measurement studies in 128.9 million children, adolescents, and adults. Lancet 2017; 390: 2627-42.

31. PHE. Excess weight and COVID-19: insights from new evidence. Public Health England, London 2020.

32. Collaboration NCDRF. Rising rural body-mass index is the main driver of the global obesity epidemic in adults. Nature 2019; 569: 260-4.

33. Bhaskar S, Rastogi A, Menon KV, Kunheri B, Balakrishnan S, Howick J. Call for action to address equity and justice divide during COVID-19. Front Psychiatry 2020; 11: 559905.

34. Candib LM. Obesity and diabetes in vulnerable populations: reflection on proximal and distal causes. Ann Fam Med 2007; 5: 547-56.

35. Stevens J, Pratt C, Boyington J, et al. Multilevel interventions targeting obesity: research recommendations for vulnerable populations. Am J Prev Med 2017; 52: 115-24.

36. Zhao Y, Li Z, Yang T, Wang M, Xi X. Is body mass index associated with outcomes of mechanically ventilated adult patients in intensive critical units? A systematic review and meta-analysis. PLoS One 2018; 13: e0198669.

37. Mukhopadhyay A, Kowitlawakul Y, Henry J, Ong V, Leong CS, Tai BC. Higher BMI is associated with reduced mortality but longer hospital stays following ICU discharge in critically ill Asian patients. Clin Nutr ESPEN 2018; 28: 165-70.

38. Donini LM, Pinto A, Giusti AM, Lenzi A, Poggiogalle E. Obesity or BMI paradox? Beneath the tip of the iceberg. Front Nutrition 2020; 7: 53.

39. Di Renzo L, Del Gobbo V, Bigioni M, Premrov MG, Cianci R, De Lorenzo A. Body composition analyses in normal weight obese women. Eur Rev Med Pharmacol Sci 2006; 10: 191-6.

40. Oga EA, Eseyin OR. The Obesity paradox and heart failure: a systematic review of a decade of evidence. J Obes 2016; 2016: 9040248.

41. Alagiakrishnan K, Banach M, Ahmed A, Aronow WS. Complex relationship of obesity and obesity paradox in heart failure - higher risk of developing heart failure and better outcomes in established heart failure. Ann Med 2016; 48: 603-13.

42. Jia X, Yin C, Lu S, et al. Two things about COVID-19 might need attention. Preprints.org; 2020.

43. Bhaskar S, Bradley S, Chattu VK, et al. Telemedicine as the new outpatient clinic gone digital: position paper from the Pandemic Health System REsilience PROGRAM (REPROGRAM) International Consortium (Part 2). Front Public Health 2020; 8: 410.

44. Bhaskar S, Bradley S, Chattu VK, et al. Telemedicine across the globe-position paper from the COVID-19 Pandemic Health System Resilience PROGRAM (REPROGRAM) International Consortium (Part 1). Front Public Health 2020; 8: 556720. 
45. Bhaskar S, Nurtazina A, Mittoo S, Banach M, Weissert R. Editorial: telemedicine during and beyond COVID-19. Front Public Health 2021; 9: 662617.

46. Batsis JA, Mackenzie TA, Bartels SJ, Sahakyan KR, Somers VK, Lopez-Jimenez F. Diagnostic accuracy of body mass index to identify obesity in older adults: NHANES 1999-2004. Int J Obes 2016; 40: 761-7.

47. Nuttall FQ. Body mass index: obesity, BMI, and health: a critical review. Nutr Today 2015; 50: 117-28. 